\title{
Experience with crosslinking in Mexican patients with keratoconus and keratometric values as prognostic factors of visual acuity
}

\author{
Experiencia con crosslinking en pacientes mexicanos con queratocono y variables \\ queratométricas como factores pronóstico de agudeza visual
}

\author{
Leopoldo Garduño-Vieyra', Claudia R. González-Sánchez', Sergio E. Hernández-Da Mota ${ }^{2,3}$ and \\ $M^{a}$. Teresa Zavala-Martínez ${ }^{2,3 *}$ \\ 'Oftalmología Garduño, Ophthalmology Clinic, Guanajuato; ${ }^{2}$ Faculty of Medicine, Universidad Michoacana de San Nicolás de Hidalgo; ${ }^{3}$ Clínica \\ David, Ophthalmology Unit. Morelia, Michoacán, Mexico
}

\begin{abstract}
Objective: The present study aimed to report the outcomes of patients with progressive keratoconus who were treated via conventional crosslinking (CXL). Method: This retrospective study included 277 eyes of 144 patients with progressive keratoconus who underwent CXL. Topographical measurements were obtained preoperatively and twelve months postoperatively. The best corrected visual acuity (BCVA), flat keratometry (K) value (K1), steep $K$ value (K2), average $K$ value (avgK), K1 axis, K2 axis, pachymetry value and cylindrical value were the studied measures. Results: At the 12-month follow-up, the mean BCVA values were improved. Statistically significant decreases in $K 1(p=0,001), K 2(p=0.000), K 1$ axis $(p=0.000), K 2$ axis $(p=0.004)$ and $\operatorname{avgK}(p=0.025)$ were observed. The correlation analysis revealed that the preoperative BCVA, K1, K2, K2 axis, avgK and cylinder as well as postoperative $\mathrm{K} 1, \mathrm{~K} 2$, avg $\mathrm{K}$ and cylinder values significantly affected visual acuity at the 12-month follow-up. Conclusions: CXL was an effective treatment to improve best corrected visual acuity. The preoperative and postoperative $K$ values, preoperative BCVA had a statistically significant correlation with BCVA at 12 months after CXL treatment.
\end{abstract}

Key words: Cornea. Keratoconus. Riboflavin. Ultraviolet rays. Crosslinking. Visual acuity.

\section{Resumen}

Objetivo: El objetivo del estudio fue describir los resultados visuales y queratométricos de pacientes con queratocono sometidos a tratamiento con crosslinking (CXL). Método: Estudio retrospectivo de 277 ojos de 144 pacientes con queratocono progresivo que se sometieron a CXL. Se obtuvieron mediciones topográficas antes del procedimiento y 12 meses después. La agudeza visual corregida (AVC), la queratometría más plana (K1), la queratometría más curva (K2), el promedio de la queratometría (Kprom), el cilindro, el eje de $K 1$, el eje de $K 2$ y el valor paquimétrico del punto de la córnea más delgado fueron las variables evaluadas. Resultados: $A$ los 12 meses de seguimiento, los valores de AVC mejoraron. Hubo disminuciones estadísticamente significativas en $K 1(p=0,001), K 2(p=0.000)$, eje de $K 1(p=0.000)$, eje de K2 $(p=0.004)$ y Kprom $(p=0.025)$. El análisis de correlación mostró que la AVC, la K1, la K2, el eje de K2, el Kprom y el cilindro preoperatorios, así

\section{Correspondence:}

*Maria Teresa Zavala Martínez

Av. México 1020, Fracc. Américas Britania

Date of reception: $17-04-2028$

C.P. 58270 , Morelia, Mich. México

Date of acceptance: 19-05-2018

E-mail: teisy_298@ hotmail.com

DOI: 10.24875/CIRUE.M18000084

Cir Cir. 2018;86(6):676-681

Contents available at PubMed

www.cirugiaycirujanos.com

0009-7411/C 2018 Academia Mexicana de Cirugía. Published by Permanyer. This is an open access article under the terms of the CC BY-NC-ND license (http://creativecommons.org/licenses/by-nc-nd/4.0/). 
como la K1, la K2, el Kprom y el cilindro posoperatorios, afectan significativamente la agudeza visual a los 12 meses de seguimiento. Conclusiones: El CXL es un tratamiento eficaz para mejorar la AVC a 1 año de seguimiento en el grupo de pacientes estudiados. Los valores de K preoperatorios y posoperatorios, y la AVC preoperatoria, se correlacionan de forma significativa con la AVC a los 12 meses de la aplicación del CXL.

Palabras clave: Córnea. Queratocono. Riboflavina. Rayos ultravioleta. Crosslinking. Agudeza visual.

\section{Introduction}

Keratoconus is a bilateral, asymmetric and degenerative cornea disease with an unknown etiology, characterized by a progressive anterior protrusion of the corneal surface and apical thinning of the stroma, which leads to important visual morbidity'. The procedure known as cross-linking $(\mathrm{CXL})$ produces a covalent bond between individual collagen fibers in order to increase anterior corneal stroma rigidity, and it is considered one of the most effective treatment modalities to stop or delay keratoconus progression ${ }^{2-4}$. In this treatment, there is a photochemical reaction between riboflavin (vitamin B2) and ultraviolet-A light (UVA); riboflavin acts as a photosensitizer to induce collagen fibers cross-linking and as a shield to protect the other intraocular structures from UVA damage ${ }^{5}$. CXL, by altering the shape and structure of the cornea, can get to improve visual acuity ${ }^{6}$.

On the other hand, CXL is known to be able to help reduce baseline keratometric values. However, changes in the cornea in the postoperative period have not been fully elucidated and require further study ${ }^{2-4}$. Even when previous studies have assessed biomechanical and clinical changes in this regard, the effects of these changes on visual acuity remain to some extent uncertain ${ }^{7}$. This study aimed to evaluate the results at 12 months in patients with progressive keratoconus treated with CXL and to determine the correlation between the studied variables.

\section{Method}

This retrospective study was approved by the local ethics committee and followed the guidelines of the Declaration of Helsinki.

Progressive keratoconus was defined as an increase in maximum keratometry $(\mathrm{K})$ of at least 1.00 diopter and loss of at least two lines of visual acuity in the course of one year. Patients with delayed epithelial healing, with a corneal pachymetry of less than 400 microns, pregnant or breastfeeding woman, with a history of corneal surgery or chemical burn were excluded from the study.
All patients underwent $\mathrm{CXL}$, which consisted of the following procedure: first, topical tetracaine was administered, $8.0 \mathrm{~mm}$ of central epithelium were removed with the use of a spatula and then riboflavin $(0.1 \%$ in $20 \%$ dextran solution) was topically administered every 3 minutes for 15 minutes. The cornea was centered and was exposed to a UVA-emitting source at a power of $3 \mathrm{~mW} / \mathrm{cm}^{2}$ and a wavelength of $370 \mathrm{~nm}$ for 30 minutes (Lightmed USA Inc., San Clemente, California, USA.). Isotonic riboflavin administration was continued every minute during UVA exposure. After treatment, the surface of the eye was washed with $20 \mathrm{ml}$ of balanced saline. At the end of the procedure a combination of antibiotic and topical lubricant was administered, and a soft contact lens was placed. The use of this contact lens was discontinued after epithelial defect closure.

Visual acuity was determined using the Snellen chart, and subsequently, conversion to logMAR units was carried out for statistical analysis. Visual capacity of all patients was recorded before the procedure and at 12 months of having been performed.

Prior to the operation and also 12 months after the procedure, the following topographic measurements were obtained using a CT-1000 corneal topographer (Towa Medical Instruments, Co., Ltd., Nakano, Nakanoshi Nagano, Japan): flattest keratometry value (K1), K1 axis, steepest keratometry value (K2), K2 axis, average keratometry (avgK), cylindrical value (topographic astigmatism) and corneal thinnest area thickness (pachymetry) using an ultrasonic pachymeter (Pachmate DGH 55, DGH Technology, Inc., Exton, PA, USA).

\section{Statistical analysis}

The SPSS software (version 21; IBM SPSS Statistics, Chicago, IL, USA) was used for statistical analysis of the results, which are presented as the mean \pm standard deviation for continuous variables. Paired Student's t-test was used for means comparison and a correlation analysis was carried out to obtain Pearson's correlation coefficient. A p-value $<0.05$ was regarded as statistically significant. 


\section{Results}

Two-hundred and seventy-seven eyes of 144 patients (70 women and 74 men; mean age: $27.03 \pm 8.65$ years) with progressive keratoconus that underwent CXL between July 2009 and January 2015 at Oftalmología Garduño, Ophthalmology Clinic of the City of León, Guanajuato, Mexico, were included.

Corrected visual acuity (CVA) showed a statistically significant improvement at the end of follow-up, compared to preoperative visual acuity $(p=0.000)$.

Preoperative pachymetry was on average 477.95 $( \pm 45.05)$. Postoperative pachymetry was not measured. The results of keratometric variables preoperatively and at the end of the follow-up are summarized in table 1 and in figures 1 to 5 . The only variable that showed no statistically significant differences between preoperative and postoperative periods was the cylinder value $(p=0.068)$.

Table 2 summarizes the results of the correlation analysis. CVA, K1, K2, the K2 axis, avgK and cylinder preoperative values, as well as $\mathrm{K} 1, \mathrm{~K} 2$, avgK and cylinder postoperative values, significantly affect visual acuity at 12 months of follow-up.

\section{Discussion}

In this study, the factors that affect visual acuity after 12 months of follow-up were analyzed in patients treated with $\mathrm{CXL}$ for progressive keratoconus, and CVA, K1, K2, K2 axis, avgK and cylinder preoperative values, as well as $\mathrm{K} 1, \mathrm{~K} 2$, avgK and cylinder postoperative values, were observed to have significant effects on final visual acuity. In particular, visual acuity was significantly improved after treatment.

Although no statistically significant differences were observed between preoperative and postoperative cylinder values, differences were identified in other values, including keratometry parameters, and many of the studied variables affected visual capacity at the end of the follow-up period, except for preoperative $\mathrm{K} 1$ axis, postoperative $\mathrm{K} 1$ and $\mathrm{K} 2$, age and pachymetry.

The fact that a negative correlation was observed between preoperative $\mathrm{K} 2$ axis values and visual acuity stands out; in other words, lower K2 axis preoperative values were associated with better visual acuity at 12 months of follow-up. On the other hand, no correlation was observed between pachymetry and final visual acuity.
Table 1. Differences between preoperative and postoperative values of the different studied variables

\begin{tabular}{lccc}
\hline & $\begin{array}{c}\text { Preoperative } \\
\text { values }\end{array}$ & $\begin{array}{c}\text { Posoperative values } \\
(\mathbf{1 2} \text { months })\end{array}$ & $\mathbf{p}$ \\
\hline CVA (logMAR) & $1.12( \pm 0.44)$ & $0.18( \pm 0.12)$ & 0.000 \\
K1 (D) & $45.41( \pm 3.53)$ & $45.38( \pm 3.88)$ & 0.001 \\
K2 (D) & $50.36( \pm 5.60)$ & $50.02( \pm 4.51)$ & 0.000 \\
K1 axis & $168.65( \pm 50.02)$ & $153.96( \pm 58.83)$ & 0.000 \\
K2 axis & $99.01( \pm 44.47)$ & $104.09( \pm 52.33)$ & 0.004 \\
Average K (D) & $47.82( \pm 5.13)$ & $47.60( \pm 5.23)$ & 0.025 \\
Cylinder (D) & $4.94( \pm 2.55)$ & $4.64( \pm 2.80)$ & 0.068
\end{tabular}

CVA: corrected visual acuity; logMAR: logarithm of minimal angle resolution; K1: flattest keratometry value; K2: steepest keratometry value; D: diopters.

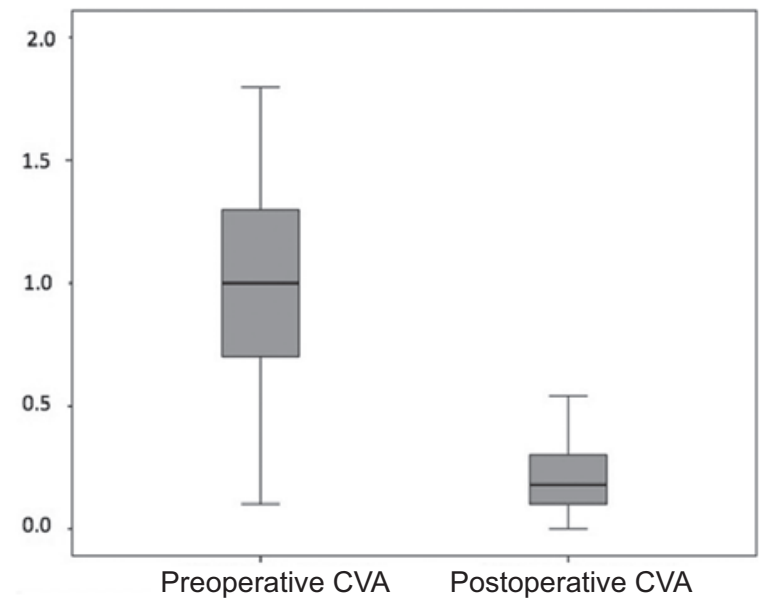

Figure 1. Box plot showing corrected visual acuity (CVA) values preoperative and postoperative distribution.

Furthermore, the correlations between final visual acuity and variables such as preoperative CVA, preoperative K1 and K2, preoperative K2 axis, postoperative $\mathrm{K} 1$ and $\mathrm{K} 2$, preoperative and postoperative avgK and cylinder were positive.

Corneal collagen CXL increases corneal biomechanical stability and is the preferred treatment for the management of progressive keratoconus ${ }^{8}$. McAnena and $\mathrm{O}^{\prime} \mathrm{Keefe}^{9}$ described the visual, refractive and topographic results following CXL in pediatric patients with keratoconus, and reported improvements in CVA and maximum $\mathrm{K}$, as well as stable minimum $\mathrm{K}$ and avgK values at one year. Sedaghat et al. $^{10}$ also reported statistically significant improvements in visual capacity and uncorrected acuity during a 1-year follow -up after $C X L$, together with a significant decrease in keratometry values and corneal apex thickness. 
Table 2. Results of the correlation analysis between the different studied variables and postoperative corrected visual acuity at 12 months

\begin{tabular}{lcc}
\hline CVA 12 months & $\mathbf{r}$ & $\mathbf{p}$ \\
\hline Age & 0.06 & 0.47 \\
Preoperative CVA & 0.38 & 0.000 \\
Preoperative K1 & 0.20 & 0.001 \\
Preoperative K2 & 0.30 & 0.000 \\
Preoperative K1 axis & -0.03 & 0.54 \\
Preoperative K2 axis & -0.15 & 0.03 \\
Postoperative K1 & 0.17 & 0.009 \\
Postoperative K2 & 0.28 & 0.000 \\
Postoperative K1 axis & -0.07 & 0.29 \\
Postoperative K2 axis & -0.04 & 0.47 \\
Preoperative avgK & 0.27 & 0.000 \\
Postoperative avgK & 0.23 & 0.000 \\
Preoperative cylinder & 0.25 & 0.000 \\
Postoperative cylinder & 0.21 & 0.002 \\
Pachymetry & -0.11 & 0.66 \\
\hline
\end{tabular}

CVA: corrected visual acuity; K1: flattest keratometry value; K2: steepest keratometry value; avgK: average keratometry.

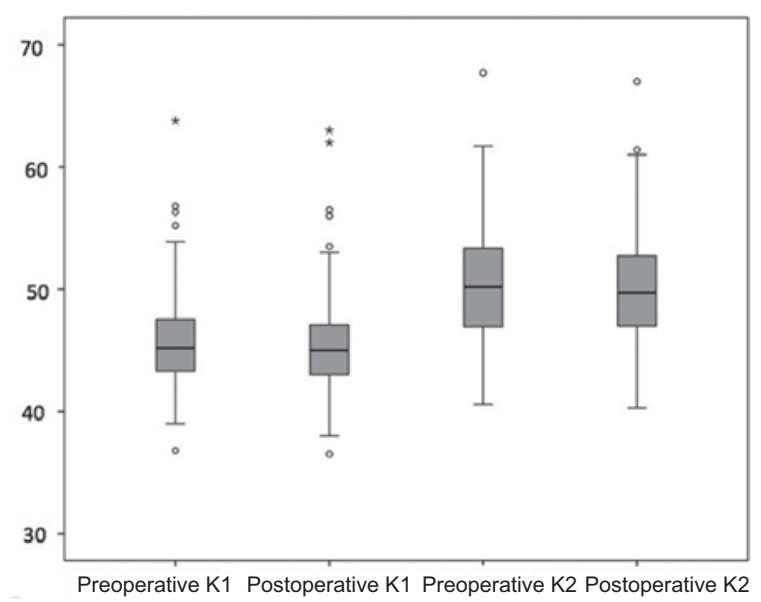

Figure 2. Box plot showing the flattest keratometry values (K1) and steepest keratometry values (K2) preoperative and postoperative distribution in diopters.

Hashemi et al. ${ }^{11}$ compared the results at 6 months of treatment with accelerated collagen $\mathrm{CXL}$ and with the standard modality for progressive keratoconus, and observed that average changes in uncorrected visual acuity and CVA, as well as average decrease in maximum $\mathrm{K}$ and avg $\mathrm{K}$ values, did not statistically significantly differ between both groups.

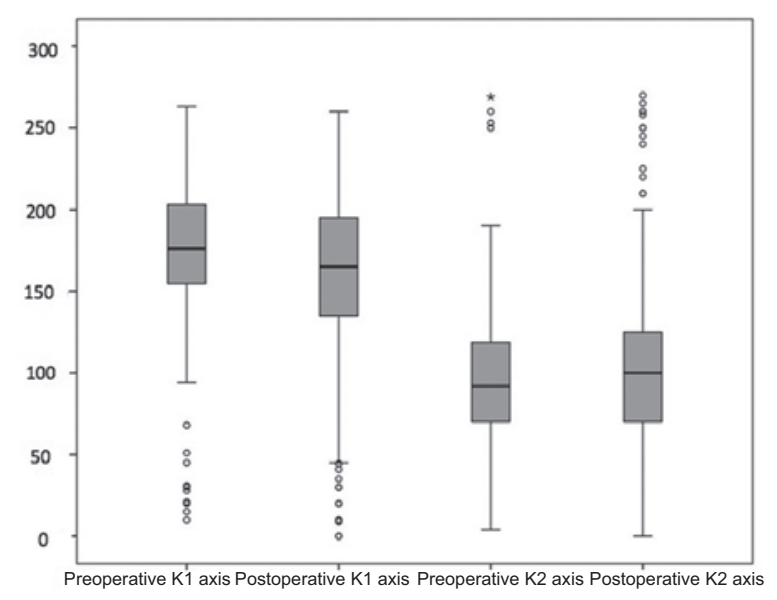

Figure 3. Box plot showing the flattest keratometry axes values (K1) and the steepest keratometry axes values (K2) preoperative and postoperative distribution in diopters.

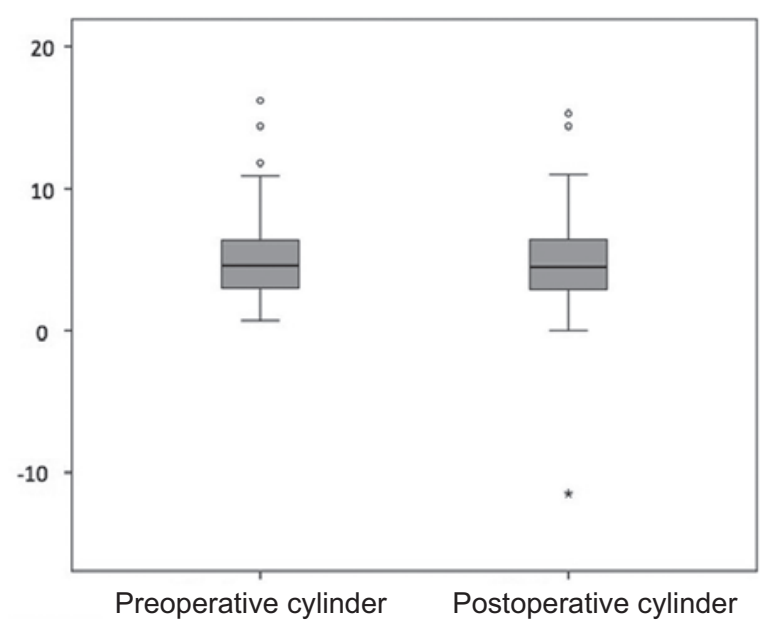

Figure 4. Box plot showing cylindrical values preoperative and postoperative distribution.

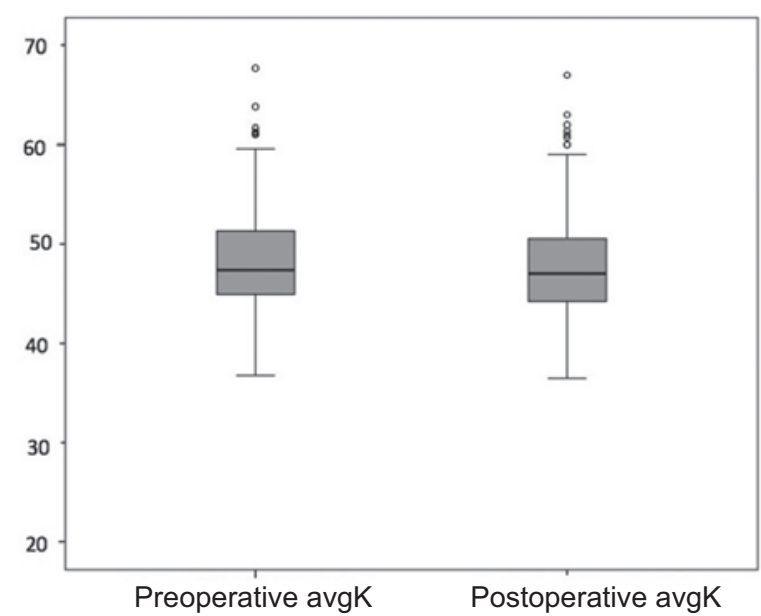

Figure 5. Box plot showing average keratometry values (avgK) preoperative and postoperative distribution in diopters. 
Berger et al. ${ }^{12}$ reported average keratometry and CVA stabilization in a boy after 12 months' follow-up after being treated with CXL. In addition to these results being similar to ours, they also support the concept that CXL has effects that limit keratoconus progression.

Elbaz et al. ${ }^{13}$ retrospectively studied the efficacy of accelerated CXL in 16 eyes with keratoconus, and reported the efficacy of this procedure in topographic parameters stabilization, including $\mathrm{K} 1, \mathrm{~K} 2$, avgK and corneal astigmatism, after 12 months of follow-up. Mita et al. ${ }^{14}$ assessed the efficacy of accelerated CXL in 39 eyes and also observed a significant improvement of uncorrected visual acuity and maximum $\mathrm{K}$ at 6 months of treatment.

A fact that is worth highlighting is the positive correlation we found between preoperative $\mathrm{K} 2$ axis and final CVA, which has not been reported, as far as we know, in other studies. This finding justifies further evaluation and to be corroborated with future studies.

On the other hand, maximum keratometric value has been considered a key topographic indicator of CXL success, and it has been reported to be stable or decreased after CXL in some studies ${ }^{14-16}$. This parameter was not assessed in our study, with this being one of its limitations.

Currently, available information on factors that affect CXL result is limited. The fact that Toprak et al. ${ }^{17}$ have reported that, in patients with progressive keratoconus, baseline age, visual acuity and pachymetry are factors that influence CXL treatment success stands out. In contrast, we did not find that age affects final visual acuity.

In their study, using CXL accelerated technique, Kirgiz et al. ${ }^{18}$ found no statistically significant differences between preoperative and postoperative keratometric values measurement, unlike us. The results of the correlation analysis of their study are similar to those found by us.

De Angelis et al. ${ }^{19}$ reported a significant improvement in 1-year postoperative CVA, but not a significant change in maximum $\mathrm{K}$. They also observed that a lower preoperative visual acuity, high refractive astigmatism and advanced keratoconus are predictive factors of better CVA. Our results agree with theirs. In this sense, we observed that there is a positive correlation, for example, with the K2 value and the cylinder value, but not with preoperative CVA, which also, according with our findings, tends to positively correlate with postoperative CVA.
As regards other limitations of our study, we can first point out the lack of a control group and randomization, and the prospective design. It also did not take into account some other topographic variables that could be correlated with the functional outcome of the procedure in the short and long term, such as anterior and posterior symmetry indices, or maximum keratometric value by topography, among others. Maximum $\mathrm{K}$, as mentioned earlier, is an important variable to assess CXL treatment success.

On the other hand, keratometry values were significantly associated with the visual result, but the study of other characteristics or intervening or confusing variables that could explain visual improvement is required. Attributing the change in visual acuity to keratometric changes is something that cannot be fully supported by the results obtained in our study. Larger and randomized studies are needed, with control groups, taking into account confusing variables and with longer follow-up periods, in order to better define the factors that affect the CXL results.

In conclusion, $\mathrm{CXL}$ was an effective treatment to improve CVA by inducing corneal flattening in this series of consecutive cases of Mexican patients, with an improvement in visual capacity.

\section{Conflict of interests}

The authors declare that there are no conflicts of interest.

\section{Funding}

The present article had no funding source.

\section{References}

1. Jeyabalan N, Shetty R, Ghosh A, Anandula VR, Ghosh AS, Kumaramanickavel G. Genetic and genomic perspective to understand the molecular pathogenesis of keratoconus. Indian J Ophthalmol. 2013;61:384-8.

2. Ghanem RC, Santhiago MR, Berti T. Topographic, corneal wavefront, and refractive outcomes 2 years after collagen cross-linking for progressive keratoconus. Cornea. 2014;33:43-8.

3. Wollensak G. Crosslinking treatment of progressive keratoconus: new hope. Curr Opin Opthalmol. 2006;17:356-60.

4. Wollensak G, Spoerl E, Seiler T. Riboflavin/ultraviolet-A-induced collagen cross-linking for the treatment of keratoconus. Am J Ophthalmol. 2003;135:620-7.

5. Iseli HP, Thiel MA, Hafezi F, Kampmeier J, Seiler T. Ultraviolet A/riboflavin corneal cross-linking for infectious keratitis associated with corneal melts. Cornea. 2008;27:590-4.

6. Greenstein SA, Fry KL, Hersh PS. Corneal topography indices after corneal collagen crosslinking for keratoconus and corneal ectasia: oneyear results. J Cataract Refract Surg. 2011;37:1282-90.

7. Goldich Y, Marcovich AL, Barkana Y, Mandel Y, Hirsh A, Morad Y, et al. Clinical and corneal biomechanical changes after collagen cross-linking with riboflavin and UV irradiation in patients with progressive keratoconus: results after 2 years of follow-up. Cornea. 2012;31:609-14. 
8. Kanellopoulos AJ. Collagen cross-linking in early keratoconus with riboflavin in a femtosecond laser-created pocket: initial clinical results. J Refract Surg. 2009;25:1034-7.

9. McAnena L, O'Keefe M. Corneal collagen crosslinking in children with keratoconus. J AAPOS. 2015;19:228-32.

10. Sedaghat M, Bagheri M, Ghavami S, Bamdad S. Changes in cornea topography and biomechanical properties after collagen cross linking for keratoconus: 1-year results. Middle East Afr J Ophthalmol. 2015;22:212-9.

11. Hashemi H, Fotouhi A, Miraftab M, Bahrmandy H, Seyedian MA, Amanzadeh K, et al. Short-term comparison of accelerated and standard methods of corneal collagen crosslinking. J Cataract Refract Surg. 2015;41:533-40.

12. Berger $Y$, Ezra-Nimni O, Skaat A, Fogel M, Grinbaum A, Barequet I. Corneal collagen cross-linking novel technique for prevention of keratoconus progression: results after one-year at the Sheba Medical Center. Harefuah. 2015;154:118-21.

13. Elbaz U, Shen C, Lichtinger A, Zauberman NA, Goldich Y, Chan CC, et al. Accelerated $\left(9-\mathrm{mW} / \mathrm{cm}^{2}\right)$ corneal collagen crosslinking for keratoconus-A 1-year follow-up. Cornea. 2014;33:769-73.
14. Mita M, Waring GO, Tomita M. High-irradiance accelerated collagen crosslinking for the treatment of keratoconus: six-month results. J Cataract Refract Surg. 2014; 40:1032-40.

15. Raiskup F, Theuring A, Pillunat LE, Spoerl E. Corneal collagen crosslinking with riboflavin and ultraviolet-A light in progressive keratoconus: ten-year results. J Cataract Refract Surg. 2015;41:41-6.

16. Derakhshan A, Shandiz JH, Ahadi M, Daneshvar R, Esmaily H. Shortterm outcomes of collagen crosslinking for early keratoconus. J Ophthalmic Vis Res. 2011;6:155-9.

17. Toprak I, Yaylalı V, Yildirim C. Factors affecting outcomes of corneal collagen crosslinking treatment. Eye (Lond). 2014;28:41-6.

18. Kirgiz A, Atalay K, Çabuk KŞ, Kaldirim H, Taşkapili M. Factors affecting visual acuity after accelerated crosslinking in patients with progressive keratoconus. Arq Bras Oftalmol. 2016;79:151-4.

19. De Angelis F, Rateau J, Destrieux C, Patat F, Pisella PJ. Predictive factors for visual outcome after corneal collagen crosslinking treatment in progressive keratoconus: one-year refractive and topographic results. J Fr Ophtalmol. 2015;38:595-606. 